\title{
Role of Neuronal Mitochondrial Metabolic Phenotype in Pathogenesis of ALS
}

\author{
Alexander Panov1,3, Nury Steuerwald1, Valentin Vavilin², \\ Svetlana Dambinova ${ }^{3}$ and Herbert L. Bonkovsky ${ }^{1}$ \\ ${ }^{1}$ Cannon Research Center, Carolinas Medical Center, Charlotte, NC, \\ ${ }^{2}$ Institute of Molecular Biology and Biophysics, Novosibirsk, \\ ${ }^{3}$ Laboratory of Brain Biomarkers, WellStar College of Health \& Human Services, \\ Kennesaw State University, Kennesaw, GA, \\ 1,3 USA \\ ${ }^{2}$ Russia
}

\section{Introduction}

Amyotrophic lateral sclerosis (ALS) is one of the group of diseases of the central nerve system (CNS), which are characterized by progressive loss of structure and function of neurons in different regions of brain or spinal cord. Therefore, these diseases are collectively designated as "Neurodegenerative Diseases" (NDDs). Usually the loss of specific functions precedes the death of affected neurons, and the related clinical features depend on localization and degree of neurodegeneration. NDDs include such diseases as Alzheimer's, Parkinson's, Huntington's, spinocerebellar ataxias, and ALS. In spite of differences in predominant localization of neurodegeneration and clinical features, there are many parallels among different neurodegenerative disorders. These include involvement of mitochondrial dysfunctions, increased oxidative stress, and atypical protein assemblies (Backman et al., 2006).

Amyotrophic lateral sclerosis (ALS) refers to several adult-onset conditions characterized by progressive degeneration of motor neurons. "Amyotrophic" refers to the muscle atrophy, weakness, and fasciculation (spontaneous contraction affecting a small number of muscle fibers) that signify disease of the lower motor neurons. There are two forms of this fatal disease: sporadic, with no known genetic component, and familial, which make up about $10 \%$ of all ALS cases (Rowland \& Schneider, 2001; Martin et al., 2009). Among the familial cases, approximately $20 \%$ are caused by dominantly inherited mutations in the $\mathrm{Cu} / \mathrm{Zn}$ superoxide dismutase (SOD1) gene, with more than 100 known mutations (reviewed in Bruijn et al., 2004). So far, there is very little information that links familial and sporadic cases of the disease. One established fact, based on studies of patients and transgenic animals, is that mitochondria dysfunction is an early manifestation. However, it is unclear whether mitochondrial dysfunctions are the primary pathogenic mechanism, or the result of some other proximate pathogenic mechanism.

Although the cases associated with mutations in the SOD1 gene comprise only about $2 \%$ of all ALS cases, understandably, transgenic animals bearing mutated SOD1 gene 
became the major targets for research on pathogenesis of ALS (Bendotti and Carri, 2004; Bruijn et al., 2004; Matsumoto et al., 2006). Of these, a transgenic mouse carrying the G93A (Gly-93 $\rightarrow$ Ala) mutant human SOD1 gene was the first described (Gurney et al., 1994). This animal model of ALS was used all over the world because it closely recapitulates clinical and histopathological features of the human disease (Matsumoto et al., 2006).

Researchers from Wyeth, John Hopkins and Harvard in collaboration with ALS Association as part of its Lou Gehrig Challenge Initiative established the SOD1G93A mutant rat line. Taconic (Germantown, NY) established a production colony in 2002, which was sponsored by grant funding from ALS Association. The original publication on this strain (tgSOD1) reported disease onset around 115 days of age, with rapid disease progression thereafter (Howland et al., 2002). Taconic has maintained a colony since 2002. In our recent work (Panov et al., 2011b) we presented data obtained in 2007 on 45 tgSOD1 animals obtained from 9 separate simultaneous isolations of BM and SCM. We studied respiration and reactive oxygen species production by mitochondria isolated from the brains $(\operatorname{tgBM})$ and spinal cords $(\operatorname{tgSCM})$, of such rats and the results obtained were highly reproducible (Panov et al., 2011b). Beginning late in 2008 and in 2009 we encountered difficulties in reproducing the results obtained in 2007. Moreover, we have found that the transgenic rat line did not develop symptoms of the disease at age of more than 200 days even though the mutated gene was evident in DNA samples from tails and ears. In 2010 we received information from Taconic (Germantown, NY) that changes in features can be attributed to a variable phenotype in this model, "which may be due to in part to both the outbred nature of the background strain as well as to possible copy number variation of the transgene" (Information Letter from Taconic). Whether these phenotypic changes were associated with the decline of the level to which the transgene was expressed is impossible to conclude because, in the rats studied in 2007, neither Taconic company, nor our lab quantified the expression of the mutated SOD1 gene or protein. Nevertheless, our comparative studies of metabolic properties of BM and SCM suggest that potentially the loss of morbidity could be explained by different patterns of substrates metabolism and associated ROS generation in BM and SCM studied in 2007 and 2010 .

In 2008 we found that BM and SCM isolated from the wild type Sprague Dawley rats began to show metabolic features that were different from those described earlier for the same strain of the wild type and tgSOD1 rats (Panov et al., 2009, 2011a). In this work we present a comparison of metabolic phenotypes and the substrate-dependent ROS generation in the wild type and transgenic rats with mutant G93A Cu/Zn-superoxide dismutase gene isolated in 2007 and 2010. We conclude that the shift in mitochondrial metabolic phenotype, which resulted in a dramatic decrease in ROS production by $\operatorname{tgBM}$ and tgSCM, may have contributed to the significant loss of morbidity of the established tgSOD1 rat line. This could result from the breeding method of the transgenic animals, when males bearing the dominant mutated SOD1 gene were mated with the wild type females. Because mitochondrial DNA has maternal inheritance (Wallace, 2001), the resulting progeny has the mitochondrial phenotype of females, and thus the mutated SOD1 protein was acting on mitochondria with different metabolism that resulted in much lower rates of ROS production. We conclude that mitochondria are the key players in the pathogenesis of ALS. 
We suggest a hypothesis, which links together pathogenic mechanisms of sporadic and familial forms of ALS. Our hypothesis is based on results obtained in experiments on animals, which showed that between species and even within one species there may exist different phenotypes of mitochondrial metabolism. Neuronal mitochondria of some phenotypes may produce very large amounts of superoxide radical, which is dismutated to hydrogen peroxide $\left(\mathrm{H}_{2} \mathrm{O}_{2}\right)$. High levels of $\mathrm{H}_{2} \mathrm{O}_{2}$ may damage the extramitochondrial isoform of superoxide dismutase (SOD1). The oxidatively damaged proteins lose $\mathrm{Cu}$ and $\mathrm{Zn}$ from the hem centers, and the demetallated protein enters mitochondrial membranes, further increases ROS production by a mechanism similar to that described for cholesterol- $\beta$-D-glucoside and fitosterol glucosides (Panov et al., 2010b), causes mitochondrial dysfunctions, and finally the death of neurons. These are sporadic cases of ALS associated with disorders of mitochondrial metabolism. The familial cases with mutations in the SOD1 gene have basically the same mechanism of motor neuron death, but, because mutated SOD1 protein is exceptionally sensitive to oxidative damage, the loss of $\mathrm{Cu}$ and $\mathrm{Zn}$ may occur at relatively low levels of $\mathrm{H}_{2} \mathrm{O}_{2}$ formation by neuronal mitochondria. The predominant involvement of spinal cord can be accounted for by metabolic and structural features of spinal cord and SCM, which were published elsewhere (Panov et al., 2011a, 2011b).

\section{General characterization of mitochondria in ALS}

Clinical features of ALS, a severe neuromuscular degenerative disease, were described by Charcot in 1874 (Rowland \& Shneider, 2001). Since that time clinical definitions (Shook and Pioro, 2009) and pathological features of the disease have been greatly expanded, aided in no small measure by advances in genetics of the disease (Rowland \& Shneider, 2001) and development of transgenic animal models of ALS (Bendotti \& Carri, 2004; Matsumoto et al., 2006; Howland et al., 2002). However, the etiology and pathogenesis of the disease remain poorly understood.

Clinical and experimental evidence showed that ALS is a systemic disease, with particular vulnerability of motor neurons due to some unique properties (Martin et al., 2007; von Lewinski \& Keller, 2005; Panov et al., 2011a). Many ALS patients are hypermetabolic, an early and persistent phenomenon (Bouteloup et al., 2009, Desport et al., 2005). Muscular mitochondrial function in amyotrophic lateral sclerosis is progressively altered in ALS patients (Echaniz-Laguna et al., 2006, Krasnianski et al., 2005), and subtle ultrastructural changes of hepatocytes and liver dysfunction have also been described in biopsy specimens from ALS patients (Nakano et al., 1987). Significant changes were also found in skeletal muscle mitochondria of transgenic SOD1 (tgSOD1) animals (Dupuis et al., 2009, Krasnianski et al., 2005). It was suggested that increased ROS generation by skeletal muscle mitochondria (Muller et al., 2007) or mitochondrial uncoupling (Dupuis et al., 2009) may be primarily responsible for the loss of neuromuscular junctions and secondary distal degeneration of motor neurons in SOD1 mice. This is an interesting and important alternative hypothesis, which requires a more detailed and critical discussion.

The paper by Muller et al. (2007) presents data on generation of ROS by skeletal muscle mitochondria (SMM) from two lines of transgenic mice bearing different mutations in SOD1 gene, SOD1 knockout mice, and mice with denervated muscle. The authors 
concluded that "enhanced generation of mitochondrial ROS may be a common factor in the mechanism underlying denervation-induced atrophy". The authors suggested also that increased ROS generation in ALS mutant model may also cause the loss of neuromuscular junctions, and thus initiate the loss of motor neurons. There are, however, experimental facts, which oppose this conclusion. Muller et al (2007) isolated skeletal muscle mitochondria using a protease nagarse for digestion of the tissue. With the nagarse method, more than $90 \%$ of mitochondria are interfibrillar. Without the protease the yields of subsarcolemmal mitochondria are very low (A. Panov, unpublished observations). ROS generated in situ by interfibrillar mitochondria are unlikely to gain access to the sarcolemmal membrane where the neuro-muscular junctions are located. This is because superoxide radical has difficulty to leave mitochondria (Panov et al. 2005). Besides, both superoxide radicals and $\mathrm{H}_{2} \mathrm{O}_{2}$ are substrates for the antioxidant enzymes in the cytoplasm, such as SOD1, catalase, etc. Rather, it is more likely that increased ROS act locally to cause damage to interfibrillar mitochondria, particularly to mtDNA, and thus cause muscle atrophy. Data presented by Muller et al. (2007) do not show direct damage to neuromuscular junctions by increased ROS. Therefore this issue requires further study. There is also a quantitative aspect of ROS generation presented by Muller et al. (2007). A comparison of the rates of ROS production by skeletal muscle mitochondria (SMM) (Figure 1 in Muller et al., 2007) and brain (BM) and spinal cord mitochondria (SCM) (see Fig. 7 in Panov et al., 2011a) shows that BM and SCM generate several times more ROS than SMM. Therefore, it is more likely that the causes of degeneration of motor neurons in ALS are associated with primary pathological processes in neurons rather than in muscle.

Dupuis et al. (2009) also concluded that "a muscle restricted mitochondrial defect is sufficient to generate motor neuron degeneration". The authors based their conclusion on mitochondrial dysfunctions observed in animals with overexpression of uncoupling protein 1 (UCP1). Overexpression of UCP1 results in deenergization of the mitochondria due to increased conductivity of the inner membrane for protons. This condition results in complete inhibition of ROS production associated with the energy-dependent reverse electron transport. The major consequence of overexpression of UCP1 is inhibition of ATP production and suppression of functions, which depend on mitochondrial ATP levels. Because in neuronal tissue reverse electron transport is the major source of ROS production (Panov et al. 2007, 2009), and increased ROS generation is one of the leading pathogenic pathways in ALS, the mechanism proposed by Dupius et al. (2009), although interesting, probably has little to do with neurodegeneration in ALS.

It was hypothesized that sporadic and familial forms of ALS may share some final pathogenic mechanisms (Bendotti \& Carri, 2004; von Lewinski \& Keller, 2005). Several pathogenic factors have been proposed (reviewed in Bruijn et al., 2004): glutamate excitotoxicity (Heath \& Shaw, 2002); mitochondrial dysfunction (Dupuis et al., 2009); increased production of reactive oxygen species (ROS) (reviewed in Barber \& Shaw, 2010) and nitroxyradicals (NO- and ONOO-) (Martin et al., 2007); deregulation of $\mathrm{Ca}^{2+}$ homeostasis and triggering of permeability transition of mitochondria (von Lewinski and Keller, 2005; Martin et al., 2009; Morota et al., 2007); induction of pro-apoptotic pathways (Przedborski, 2004); misfolding and intracellular accumulation of mutant SOD1 (Tateno et al., 2004), including in brain and spinal mitochondria (Liu et al., 2004; Higgins et al., 2002); mutant SOD1-induced conformational changes in Bcl-2 (Pedrini et al., 2010) and VDAC1 (porin) 
(Israelson et al., 2010); and abnormal axonal transport (Magrane \& Manfredi, 2009). However, almost all of these proposed pathogenic mechanisms directly or indirectly involve mitochondria. The major problem in searching for alternative pathogenic mechanisms, in case of severe mitochondrial disability, is that practically all cellular and organ functions depend on energy and thus also become disturbed (Gershoni et al., 2009). Therefore, it is of paramount importance to precisely understand the nature and causes of mitochondrial dysfunctions, and whether they are early or late events in disease evolution.

In the majority of studies of ALS, the mitochondrial abnormalities were assessed using morphological methods, which showed swollen brain and spinal mitochondria with dilated cristae, and vacuoles in matrix (Sasaki et al., 2004, Jaarsma et al., 2006). It was suggested that vacuolization may depend on accumulation amount, rather than from toxic property, of mutant SOD1 (Jaarsma, 2006). Morphologic methods, including quantitative histochemistry, and immunological methods, showed that both in ALS patients and tgSOD1 animals, the activities of respiratory chain complexes were diminished (Jung et al., 2002), and that the spinal cord mitochondria are predisposed to opening of the $\mathrm{Ca}^{2+}$-dependent permeability transition pores (mPTP), which trigger death of motor neurons (Martin et al., 2009). There is a large body of evidence that spinal cords in tgSOD1 animals are subjected to increased oxidative and nitrative stress, as indicated by accumulation of protein carbonyls and nitrated proteins (Martin et al., 2007, 2009). These data also demonstrated that mitochondria are involved early in the pathogenesis of ALS (Martin et al., 2007, 2009). Recently, Panov et al. (2011b) provided direct evidence that isolated mitochondria from the brain and spinal cord of tgSOD1 rats generate significantly more reactive oxygen species (ROS) as compared with mitochondria from wild type animals.

Morphological, histochemical and immunological methods provided important information about involvement of mitochondria in the pathology, however they do not tell us what caused the changes in mitochondrial morphology. Relatively few studies were performed on isolated BM and SCM mitochondria from control (Sullivan et al., 2004, Panov et al., 2011a), tgSOD1 animals (Kirkinezos et al., 2005, Damiano et al., 2006, Fischer et al., 2011, Panov et al., 2011b), Wobbler mice (Dave et al., 2003, Xu et al., 2001), or mnd mice, which spontaneously develop motor neuron pathology (Bertamini et al., 2002). In their pioneering work, Sullivan et al (2004) have shown that normal SCM have lower respiratory activity, lower threshold for calcium-induced mitochondrial permeability transition, and a higher degree of superoxide radical production (determined with dehydroethidium) and lipid peroxidation as compared with BM. However, the dehydroethidium method does not identify the origin of superoxide radical. Studies of isolated mitochondria from tgSOD1 mice showed that BM and SCM had decreased rates of respiration associated with the loss of complex IV activity (Kirkinezos et al., 2005). Very early in the course of the disease, the mitochondrial $\mathrm{Ca}^{2+}$ loading capacity was significantly diminished as compared with the age-matched control mice (Damiano et al., 2006). Respiratory activities were also diminished in SCM of Wobbler mice (Dave et al., 2003, Xu et al., 2001) and mice with motor neuron degeneration disease (Bertamini et al., 2002).

A comparative study of isolated normal and tgSOD1 brain and spinal cord mitochondria was published recently by Panov et al. $(2011 a, b)$, and the unique metabolic features of BM and SCM were described (see also Panov et al, 2009). Normal SCM produced significantly more ROS than BM, and this was associated with the succinate-dependent reverse electron transport (Panov et al. 2011a). A rather unexpected finding was that BM and SCM isolated 
from presymptomatic tgSOD1 rats showed almost normal rates of oxidative phosphorylation. Panov et all. (2011b) purified mitochondria in a Percoll gradient, and thus eliminated damaged mitochondria. This resulted in significantly lower yields of mitochondria per 1 gram of tissue of tgSOD1 rats: the yields were diminished by $27 \%$ for the brain and by $58 \%$ for spinal cord as compared with the normal Sprague Dawley rats (Panov et al., 2011b). Avossa et al. (2006) used immunocytochemistry and electron microscopy techniques to compare wild type and G93A spinal cord tissues after 14 days of growth under standard in vitro conditions. Wild type and mutant cultures displayed no differences in the analyzed parameters as well as in the number of motor neurons, and there were no signs of mitochondria vacuolization or protein aggregate formation in G93A ventral horns. Together, the results of Panov et al. (2011b) and Avossa et al. (2006) suggest that in tgSOD1 rats the BM and SCM are primarily normal but suffer from some pathological events, which rapidly deteriorate mitochondria and cause death of neurons.

In order to better understand the metabolic events involved in putative pathological mechanisms of neurodegeneration, we have to discuss the distinctive features of brain and spinal cord energy metabolism and their mitochondria.

\section{General features of neuronal energy metabolism}

Neuronal cells are strictly aerobic and require large quantities of ATP produced at high rate in order to function normally. Humans brain constitutes only $2 \%$ of the body's weight, but accounts for $20 \%$ of its resting $\mathrm{O}_{2}$ metabolism (Attwell \& Laughlin, 2001). However, even in humans, heart and kidney consume significantly more oxygen per unit of the organ's mass than the brain (Rolfe \& Brown, 1997). In rats, liver, kidney and heart consume correspondingly 2, 3 and 3.9 times more oxygen than the brain (Rolfe \& Brown, 1997). Thus it is not the necessity for the high rate of oxidative metabolism that is unique for the central nerve system, but how the oxidative metabolism is organized in neuronal cells.

Cortical tissue is composed mainly of two types of cells: the nerve cells (or neurons) and the neuroglial cells (or glia). Glial cells greatly outnumber the neurons (Abeles, 1991; Attwell \& Laughlin, 2001; Stolzenburg et al., 1989). Glial cells do not directly take part in the interactions between neurons, but play an important role in maintaining neuronal metabolism and in directing the development and growth of the brain. The classical categorization of neurons was based mainly on morphology of the cell body and its dendritic tree, and to a lesser extent on the morphology of the axon and its branches (Abeles, 1991).

There are two main categories of the cortical cells according to their physiological effects on each other: excitatory and inhibitory cells. Excitatory cells release transmitters (glutamate) at their synaptic ends that, on contact with the postsynaptic membrane, create ion currents that depolarize the postsynaptic cell. Inhibitory cells release transmitters, such as $\gamma$-aminobutyric acid (GABA), that tend to hyperpolarize the postsynaptic cell or to increase the conductance of the postsynaptic membrane to chloride, thereby diminishing the effects of the depolarizing currents generated by the excitatory synapses. Excitatory synapses dominate the brain's grey matter because excitatory neurons outnumber inhibitory cells by a factor of 9 to 1, and $90 \%$ of synapses release glutamate (Abeles, 1991; Braitenberg \& Schüz, 1998). The distribution of mitochondria points to these glutamatergic synapses as the major users of metabolic energy (Wong-Riley, 1989; Attwell \& Laughlin, 2001).

More than $80 \%$ of neuronal mitochondria are located in the dendrites and axonal terminals (Wong-Riley, 1989; Attwell \& Laughlin, 2001). With high synaptic density of $8 \times 10^{8}$ per 1 
$\mathrm{mm}^{3}$ in all cortices (the density of synapses is not very much different among species) it is clear that in the brain most energy expenditures are associated with synaptic activity, where most mitochondria are located (Abeles, 1991). The close spacing of terminals along axons (5 $\mu \mathrm{m}$, implying a diffusion time of only 25 milliseconds) make terminal and axonal mitochondria functionally indistinguishable (Attwell \& Laughlin, 2001).

Neurons communicate by means of signals that lead to depolarization of their excitable membranes. The degree of depolarization of the dendritic or soma membranes is determined by complex interactions between excitatory and inhibitory transmitters. The depolarization spreads to the axon, leading to release of an excitatory or inhibitory transmitter at the axonal endings of the cell, thus allowing information to be transferred to the next cell. When impulses are propagated, the cell loses $\mathrm{K}^{+}$and gains $\mathrm{Na}^{+}$, and in order to preserve excitability the cell must extrude $\mathrm{Na}^{+}$and accumulate $\mathrm{K}^{+}$, using metabolic energy derived from oxidative metabolism (Abeles, 1991). Postsynaptic ion fluxes $\left(\mathrm{Na}^{+}, \mathrm{K}^{+}, \mathrm{Cl}-\right)$ and presynaptic $\mathrm{Ca}^{2+}$ influx consume in grey matter approximately $75 \%$ of the brain's energy (Abeles, 1991; Attwell \& Laughlin, 2001). Because depolarization and restoration of ionic composition across the neuronal membrane occur in the millisecond scale, neuronal mitochondria must provide large quantities of ATP in a very short time. This distribution of energy use reflects the fact that a chemical synapse is an amplifier: for each glutamate released approximately 100 ions enter the postsynaptic terminal (Abeles, 1991). The rest (25\%) of the brain's energy is used for the basic "housekeeping" functions, such as maintenance of $\mathrm{pH}$ gradients, asymmetrical distributions of phospholipids in membrane bilayers, protein synthesis (about $2 \%$ ), anaplerotic functions and recycling of glutamate from synaptic clefts (Attwell \& Laughlin, 2001). It was suggested that white and grey matter require similar amounts of energy on basic (nonsignaling) cellular activities (Attwell \& Laughlin, 2001).

It is widely accepted that nerve tissues of adult mammals use glucose as the major source of energy. To fully understand the specifics of energy metabolism in brain, it is important to take into account that, in dendrites and synaptic terminals, there is limited space for glycolytic enzymes that would provide mitochondria with enough pyruvate derived from glucose. Therefore, neurons cannot be functionally and metabolically regarded without astroglia. Astrocytes provide neurons with lactate, as the major source of energy, replenish the neuronal pool of glutamine and recycle glutamate (Ebert et al., 2003; Pellerin et al., 2007; Suzuki et al., 2011). Of the total energy consumed by the brain, approximately $80 \%$ of energy expenditure is satisfied by oxidation of glucose and $20 \%$ by oxidation of fatty acids (Ebert et al., 2003). As we will see later, neurons also oxidize significant amounts of glutamate and GABA as a source of energy. The neurotransmitter GABA is formed from glutamate by the action of glutamate decarboxylase. It appears that glutamine serves as the precursor for glutamate and GABA. Therefore, the pool of glutamine must be constantly replenished in anaplerotic reactions, which occur predominantly in astroglia.

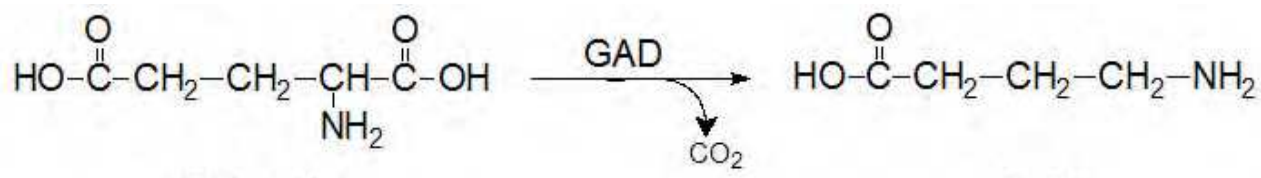

Glutamate

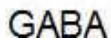

Fig. 1. Formation of GABA from glutamate. GAD - glutamate decarboxylase. 
Because anaplerotic functions of astrocytes require energy, oxidation of fatty acids occurs in glial mitochondria (Ebert et al., 2003) providing energy and saving glucose for production of lactate in aerobic glycolysis and a-ketoglutarate for synthesis de novo neuromediators glutamate and GABA (Waagepetersen et al., 1999; Ebert et al., 2003). Glutamine synthetase is an astrocytespecific enzyme (Norenberg \& Martinez-Hernandez, 1979), and during octanoate oxidation in astrocytes most of the anaplerotic flux in brain is occurring in the TCA cycle associated with glutamine production (Ebert et al., 2003). In order to fulfill the task of metabolic provision of neuronal functions there are several mechanisms that ensure functional and metabolic compartmentalization and complementation between neurons and astroglia, which thus exclude competition for energy substrates. Neuronal mitochondria do not possess the full range activity of $\beta$-oxidation enzymes, whereas glial mitochondria readily oxidize fatty acids (Ebert et al., 2003). On the other hand, glial mitochondria do not have active glutamate-aspartate translocase (Berkich et al., 2007), which is the key enzyme of the malate aspartate shuttle and the major pathway for oxidation of glutamate by neuronal mitochondria. Thus astrocytes do not utilize glutamate as a respiratory substrate. The distribution of lactate dehydrogenase isoforms between glial cells and neurons promotes aerobic glycolysis in astroglia and utilization of lactate by neurons as the major respiratory substrate (Pellerin et al., 2007).

\section{In activated neurons mitochondria utilize a mixture of substrates}

Mitochondria are devices for burning hydrogen producing water and releasing energy, a large part of which is accumulated as electrochemical transmembrane potential $\left(\Delta \mu_{\mathrm{H}^{+}}{ }^{+}\right.$ (Mitchell, 1977; Nicholls, 2008). $\Delta \mu_{\mathrm{H}^{+}}$is utilized for production of ATP, and other useful work in the mitochondria and cell. Therefore lactate, which has additional hydrogen, as compared with pyruvate, has higher energetic value for neuronal mitochondria. In the cytosol of a neuron, lactate is oxidized to pyruvate in the reaction catalyzed by lactate dehydrogenase $(\mathrm{LDH}): \mathrm{NAD}^{+}+$Lactate $\rightarrow \mathrm{NADH}+\mathrm{H}^{+}+$Pyruvate. Pyruvate is transported into mitochondria and metabolized.

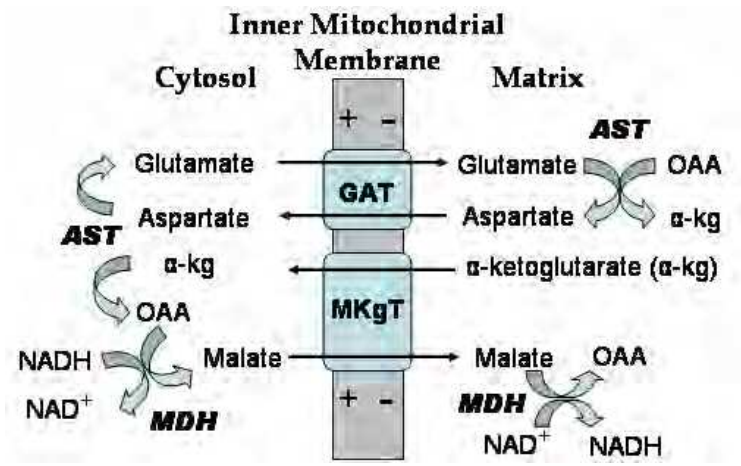

Abbreviations: AST - aspartate aminotransferase; GAT - glutamate-aspartate transporter, $\mathrm{MDH}$ malate dehydrogenase; MKgT - malate- $a$-ketoglutarate transporter; OAA - oxaloacetate

Fig. 2. The malate aspartate shuttle. In a cell with respiring energized mitochondria the malate aspartate shuttle serves for transport and oxidation of hydrogen from cytosolic $\mathrm{NADH}$ to mitochondrial respiratory chain. The process is unidirectional because GAT is electrogenic and the matrix NADH is rapidly oxidized by respiratory chain. 
In order to rapidly oxidize lactate to pyruvate, the cytosolic NADH must be oxidized back to $\mathrm{NAD}^{+}$. In neurons the task of reoxidation of the cytosolic NADH and transport of hydrogen into mitochondria occur via a number of functionally coupled cytosolic and mitochondrial enzymes, which form the malate-aspartate shuttle (MAS) (Figure 2). Glutamate is a necessary component of MAS. Because nonsynaptic and presynaptic neuronal mitochondria effectively oxidize glutamate (Yudkoff et al. 1994), neuronal cells constantly have to replenish the cytosolic pool of glutamate.

Until recently, it was generally accepted that most of the glutamate is rapidly removed from the synaptic cleft by glutamate transporters EAAT1 (GLT-1) and EAAT2 (GLAST) located on presynaptic termini and glial cells (Furness et al., 2008). However, recent data show that a significant fraction of glutamate is rapidly bound and transported by the glutamate transporter isoform, EAAT4, located juxtasynaptically in the membranes of spines and dendrites (Auger \& Attwell., 2000; Brasnjo\& Otis., 2004). EAAT4 protein was found to be omnipresent throughout the fore- and midbrain (Massie et al., 2008). These data suggest that postsynaptic transport of glutamate into nerve terminals, where mitochondria are located (Abeles, 1991), may occur in all brain regions. According to calculations of Brasnjo and Otis (2004), in a single synapse EAAT4 bind and transport postsynaptically about $1.3 \pm 0.1 \times 10^{6}$ glutamate molecules. In the brain, on average, $1 \mathrm{~mm}^{3}$ of tissue contains $1 \times 10^{8}$ synapses (Abeles, 1991; Nicholls, 1993). Because of the high density of synaptic contacts, the neuronal cells may be exposed to mediators released from hundreds of firing synapses. Thus in a narrow space of spines and dendrites several million glutamate molecules postsynaptically transported from synaptic boutons may create local cytosolic concentration of glutamate in a low $\mathrm{mM}$ range. Consequently, neuronal mitochondria, particularly those located at the axonal or dendritic synaptic junctions may temporarily metabolize, in addition to pyruvate, some amounts of glutamate (Yudkoff et al. 1994; Panov et al. 2009). Besides, GABA is also transported postsynaptically where it is catabolized in mitochondria to succinate (Tillakaratne et al., 1995).

As we have mentioned, for rapid conversion of lactate to pyruvate, postsynaptic neurons must receive a certain amount of glutamate to fuel MAS to recycle cytosolic NAD ${ }^{+}$ (Berkich et al., 2007). Importantly, the activity of the brain mitochondrial isoform of aspartate glutamate transporter is controlled by $\mathrm{Ca}^{2+}$ (Pardo et al., 2006). Therefore increased neuronal activity through small changes in the extramitochondrial $\mathrm{Ca}^{2+}$ activates MAS, whereas increased mitochondrial $\mathrm{Ca}^{2+}$ activates mitochondrial respiration (Nicholls, 2009).

There is evidence (Yudkoff et al., 1994), that in the presence of glutamate + pyruvate, the tricarboxylic acid (TCA) cycle in brain mitochondria operates as two coupled cycles: one (cycle A) leads from a-KG to OAA, and another (cycle B) from OAA to a-KG that includes the citrate synthase reaction (see figure 3). According to Yudkoff et al. (1994), the flux of substrates through cycle A is 3-5-fold faster than that through the cycle B. Thus, with pyruvate + glutamate + malate, activation of a-ketoglutarate dehydrogenase complex ( $\alpha$ $\mathrm{KGDHC}$ ) and succinate dehydrogenase (SDH) may significantly increase the rates of the tricarboxylic acid cycle (TCA) cycle and respiratory chain in state 3 and state $3 \mathrm{U}$ (Fig. 3). A high turnover of cycle $\mathrm{A}$ with activated $\mathrm{SDH}$ would increase reverse electron transport (RET) and the associated ROS production. 


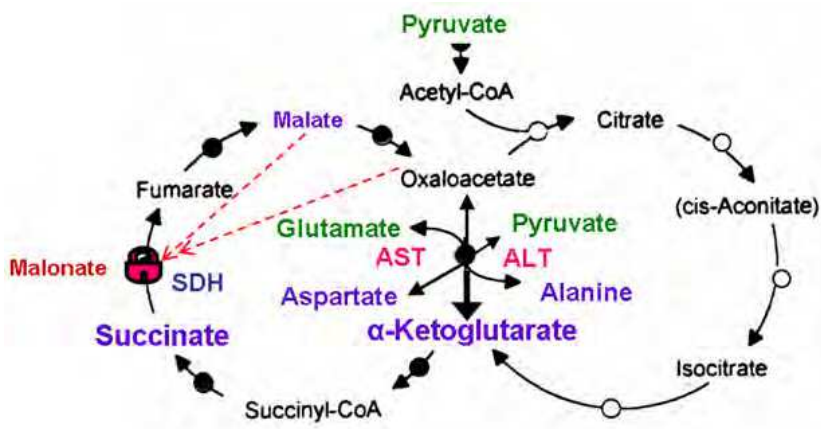

A

B

Abbreviations: ALT - alanine aminotransferase; AST -aspartate aminotransferase; SDH - succinate dehydrogenase (Complex II).

Fig. 3. The tricarboxylic acid cycle in the presence of pyruvate and glutamate operates as two coupled cycles A and B. In the presence of glutamate and/or pyruvate as substrates high activities of AST and ALT may "short-circuit" oxaloacetate and a-ketoglutarate, thus converting the "normal" TCA cycle into two independently operating cycles A and B. Malonate is a quasi-irreversible inhibitor of $\mathrm{SDH}$, whereas oxaloacetate (OAA) is a competitive but strong inhibitor. SDH has similar affinities for succinate and malate, but oxidation of malate results in formation of OAA on the enzyme's active center, which makes malate a strong inhibitor of SDH.

Thus in activated neurons mitochondria may oxidize simultaneously glutamate, pyruvate, and metabolites of the TCA cycle, such as malate, and succinate. Postsynaptically transported GABA is catabolized in mitochondria to succinate (Tillakaratne et al., 1995). Under these conditions, brain (BM) and spinal cord (SCM) mitochondria significantly increase the rate of oxidative phosphorylation and the succinate-dependent production of ROS (Panov et al., 2009, 2011a). With glutamate + pyruvate + malate as substrates, increased production of ATP and ROS was associated with dramatic increase in the matrix concentration of a-ketoglutarate (Balasz, 1965a) due to increased activities of mitochondrial aminotransferases AST and ALT (Fig. 3). Under these conditions glutamate dehydrogenase (GLDH) does not participate in production of a-KG (Balasz, 1965b). Since AST and ALT are present in great excess, compared with the respiration rate, the oxaloacetate (OAA) formed is continuously removed by the transamination reactions. Balazs (1965b) concluded that a competition takes place between the a-KGDHC and GLDH, probably for NAD+, resulting in preferential oxidation of a-oxoglutarate.

\section{Distinctive properties of ROS generation in brain and spinal cord mitochondria}

In neuronal tissue mitochondria are the major source of ROS production (Stowe \& Camara, 2009), which is indispensable feature of aerobic metabolism. It is generally accepted that during oxidation of the NAD-dependent substrates the limiting step is at the NADH-dehydrogenase site of Complex I (see Panov et al. 2007, 2009). With succinate as a substrate, production of ROS is significantly higher, because Complex II, which is 
also part of the TCA cycle - succinate dehydrogenase (SDH), feeds electrons into the mitochondrial pool of $\mathrm{CoQ}_{10}$ (ubiquinone, $\left.\mathrm{Q}\right)$. The reduced ubiquinone $\left(\mathrm{QH}_{2}\right)$ in its turn reduces the sites on Complex I that can generate superoxide radicals at high rate. This process, known as reverse electron transport, is energy-dependent and inhibited by rotenone. Some researchers deny the significance of succinate in ROS production on the pretext that succinate concentration is too low in mitochondria (Starkov, 2008; Stowe \& Camara, 2009; Zoccarato et al., 2007). As we have shown recently, however, brain and spinal cord mitochondria may produce succinate even in the presence of pyruvate + malate (Panov et al., 2009) , and as we show in this article (see Fig. 6) even with glutamate + malate a large part of ROS production may be associated with oxidation of succinate. However a particularly large production of the succinate-dependent ROS was observed in the presence of glutamate + pyruvate + malate (Panov et al., 2009, 2011a, 2011b). With these substrates the increased succinate oxidation was caused by a dramatic increase in mitochondrial a-ketoglutarate due to high activities of aminotransferases (Balasz, 1965a, 1965b). Besides, GABA is catabolized with formation of succinate in postsynaptic mitochondria (Tillakaratne et al. 1995). Thus, in the excited neurons succinate is an indispensable mitochondrial metabolite. In this paper we provide evidence that ROS generation associated with the succinate-dependent reverse electron transport is a subject for phenotypic variations.

Another objection to the importance of reverse electron transport (RET) in ROS generation argues that, because RET is energy-dependent, in the functioning cell the diminished mitochondrial energization will inhibit production of ROS (Starkov, 2008). The latter objection is valid for the most perpetually functioning organs, such as heart, kidney and liver. But it is only partially applicable to brain and spinal cord where a very large number of mitochondria are located at axonal and dendritic junctions (Wong-Riley, 1989). At the narrow spaces of synaptic junctions there is no other task for mitochondria beside provision of ATP for restoration of ionic composition in excited synapses. If the neurons are not excited, mitochondria become fully energized and produce ROS at high rate. Therefore axonal and synaptic junctions, including neuro muscular junctions, are particularly vulnerable to oxidative damage if neurons are not excited for some reason.

Another possible reason why the succinate-dependent ROS production was underrated could be the fact that most researchers use "classical" mixtures of substrates, such as glutamate + malate, pyruvate + malate, succinate alone, or, very often, in the presence of rotenone.

Figure 4 shows a representative experiment with the BM and SCM isolated in 2007 from tg SOD1 rats. One can see that with glutamate + malate, the rate of ROS production, measured as $\mathrm{H}_{2} \mathrm{O}_{2}$, there were no differences between $\operatorname{tgBM}$ and $\operatorname{tgSCM}$, wtBM or wtSCM (not shown). With pyruvate + malate as substrates, tgSCM generated significantly more ROS than tgBM (see Fig. 5). This was because SCM in general oxidize succinate at higher rate than $\mathrm{BM}$, presumably due to the lower intrinsic inhibition of SDH by oxaloacetate (Panov et al., 2011a). However, when tgBM and tgSCM oxidized a mixture of glutamate + pyruvate + malate, there was a several-fold increase in ROS production. TgSCM produced much more ROS than tgBM (Fig. 4, see also Fig. 6 in Panov et al., 2011b). Thus the usage of physiologically relevant mixtures of substrates is far more informative for understanding the role of mitochondria in pathogenesis of diseases, than the "classical" approach. 


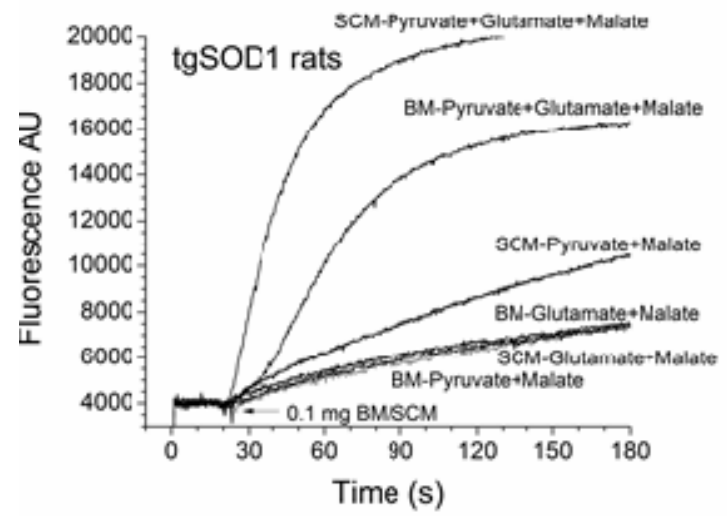

Fig. 4. Production of ROS by brain and spinal cord mitochondria from tgSOD1 rats.

Mitochondrial production of ROS was registered as $\mathrm{H}_{2} \mathrm{O}_{2}$ by Amplex red method (Panov et al., 2009).

We suggested the following metabolic scenario for the neuronal mitochondria located at synaptic junctions. During neuronal activity, the postsynaptic mitochondria are exposed to increased levels of pyruvate and glutamate, which enhance ATP production due to specific interactions between the glutamate transforming enzymes and the TCA cycle enzymes. This effect of the substrate mixtures is specific for the BM, and SCM (Panov et al., 2009, 2011a). As soon as activation of a synapse comes to an end, transport of glutamate from the synaptic cleft would also stop. As a result, activation of respiration induced by the simultaneous presence of glutamate and pyruvate will also end because glutamate becomes exhausted. Thus the neuromediator glutamate controls energy metabolism in brain not only at the level of astrocytes by enhancing production of lactate, but also at the level of neurons by controlling the activity of MAS and specific interactions between aminotransferases.

In the absence of neuronal activation, SDH (Complex II) in the postsynaptic mitochondria is inhibited by OAA (Panov et al. 2010a). The physiological significance of this inhibition is to prevent excessive ROS production associated with reverse electron transport. This is particularly important for neurons because with pyruvate, which is the major mitochondrial substrate in resting neurons (Pellerin et al., 1994; Hertz, 2004), there is a substantial production of succinate and thus a possibility of increased RET-dependent ROS production (see Fig. 5A, 5B; Panov et al. 2009, 2011a, 2011b). During increased neuronal activity glutamate and pyruvate temporarily release the inhibition of SDH. Increased ATP production (state 3) prevents generation of ROS (Starkov, 2008; Votyakova \& Reynolds, 2001). Because SCM in general oxidize succinate at higher rates than BM, due to lower intrinsic inhibition of SDH, they are more vulnerable to oxidative stress than BM (Panov et al., 2011a, 2011b).

Activation of oxidative phosphorylation and increased ROS generation with pyruvate + glutamate + malate was observed only with BM and SCM (Panov et al., 2009, 2011a). However, activation of succinate oxidation by pyruvate and glutamate may be a common phenomenon for mitochondria from many organs. Our experiments with mitochondria from different organs and different species of rats and mice, and with one species (Sprague Dawley) of rats over period of 6 years, have shown that mitochondrial metabolism is a 
subject to phenotypic variations between species and in one species with time (Panov et al., 2010). Below we describe how changes in mitochondrial metabolism of BM and SCM of wild type Sprague Dawley rats affected mitochondrial dysfunctions in tgSOD1 rats in 2007 and 2010.

\section{Differences between BM and SCM isolated in 2007 and 2010 in the rates of ROS production with different substrates}

ROS production by mitochondria strongly depends on the metabolic state of the mitochondria, type of substrates, and is also tissue-specific (Kwong, Sohal, 1998; Muller et al., 2008, Panov et al., 2007). There are two types of ROS production by mitochondria energy-dependent and non-energy-dependent (Panov et al., 2007). The energy-dependent ROS production is associated with the reverse electron transport (Kwong, Sohal, 1998; Muller et al., 2008, Panov et al., 2007). ROS production, which does not depend on energization and the metabolic state of the mitochondria may occur on complexes I, II and III and depends on the presence of inhibitors of the electron transport (Kwong, Sohal, 1998; Panov et al., 2007; St-Pierre et al. 2002). In the absence of respiratory inhibitors the rate of the non-energy dependent ROS production is relatively slow (Panov et al., 2007). We have shown that in BM and SCM the major source of ROS correlates with the reverse electron transport, which occurs during oxidation of succinate (Kwong, Sohal, 1998; Panov et al., 2007, 2009, 2011a, b), fatty acids (Panov et al., 2010c), or a-glycerophosphate (Tretter et al., 2007). Thus respiration rates in State 4 in the well coupled mitochondria oxidizing succinate correlates with the rates of ROS production (Panov et al., 2007, 2011a). Therefore changes in the rates of ROS production presented in Figure 4 closely reflect metabolic pattern of the mitochondria. Another reason why we do not present respiratory data is that in 2010 we had limited number of tgSOD1 rats, which precluded obtaining statistically significant data with all substrates and their mixtures.

In our studies on mitochondrial dysfunctions in the rat model of ALS (tgSOD1), we used as a reference control Sprague Dawley rats from Taconic (Germantown, NY). In the years of 2005-2007 we have discovered, that in this strain both BM and SCM had a unique metabolic attribute, which was absent in mitochondria from other organs: during simultaneous oxidation of pyruvate + glutamate + malate the rates of oxidative phosphorylation and the State 4 ROS production were significantly higher than with either glutamate or pyruvate alone (Panov 2009, 2011a). This substrate mixture corresponded to the metabolic situation in activated neurons (Panov et al., 2009). Addition of malonate, a potent inhibitor of SDH, attenuated the rates of respiration and ROS production with pyruvate + malate and glutamate + pyruvate + malate to the level with glutamate + malate.

With succinate as a substrate, ROS production was several times higher than with glutamate + pyruvate + malate, and was further increased in the presence of glutamate + pyruvate (Fig. 5A, 5B). The stimulation of the succinate-supported State 4 respiration and ROS production by glutamate and pyruvate was attributed to removal of endogenous oxaloacetate, which inhibits succinate dehydrogenase (SDH) (Panov et al. 2009, 2010). SCM from the control rats produced significantly more ROS than $\mathrm{BM}$, particularly with the succinate containing substrate mixtures (Figure 5A, 5B; see also Panov et al. 2009, 2011a). We have concluded that in BM the activity of SDH was primordially inhibited by endogenous oxaloacetate (Panov 2009, 2010). This intrinsic inhibition of SDH by oxaloacetate was less evident in SCM, and therefore SCM produced more ROS with substrate mixtures that 
produced or contained succinate (Panov 2011a). The described above metabolic features of $\mathrm{BM}$ and SCM were consistently observed in the wild type and tgSOD1 rats during period of 2005 - 2007 years (Panov et al. 2009, 2011a, 2011b).
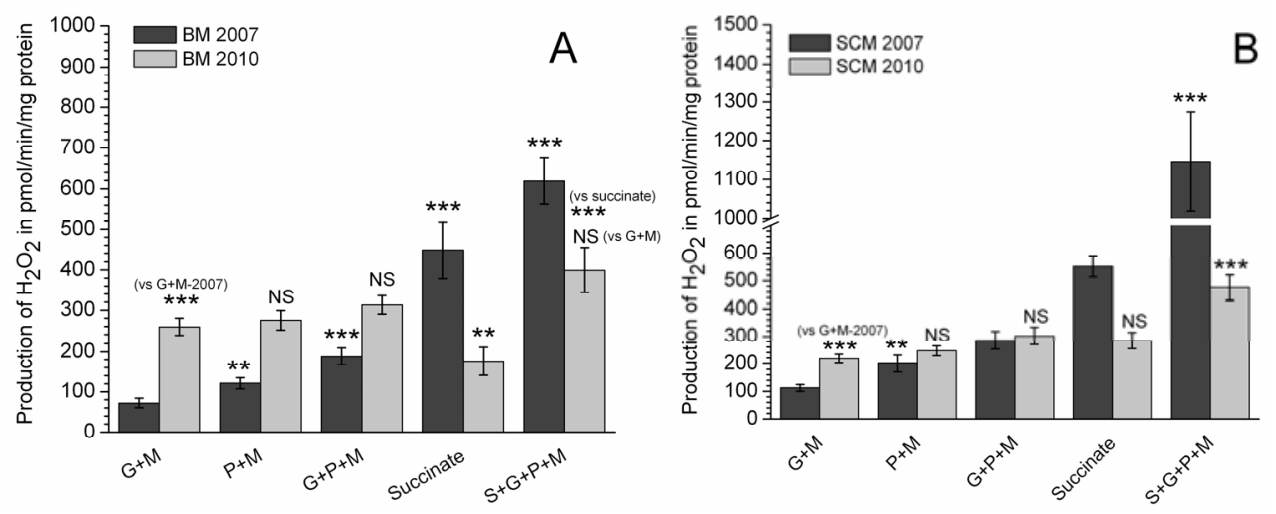

A. Brain mitochondria; B. Spinal cord mitochondria. Dark grey - wild type rats in 2007, light gray wild type rats in 2010. Mitochondria were incubated in a medium containing: $125 \mathrm{mM} \mathrm{KCl}, 10 \mathrm{mM}$ MOPS, pH 7.2, $2 \mathrm{mM} \mathrm{MgCl}_{2}, 2 \mathrm{mM} \mathrm{KH}_{2} \mathrm{PO}_{4}, 10 \mathrm{mM} \mathrm{NaCl}, 1 \mathrm{mM}$ EGTA, $0.7 \mathrm{mM} \mathrm{CaCl}$. At a Ca2 ${ }^{2+}$ EGTA ratio of 0.7 , the free $\left[\mathrm{Ca}^{2+}\right]$ is close to $1 \mu \mathrm{M}$ as determined using Fura-2. The substrate concentrations were: $5 \mathrm{mM}$ succinate without rotenone, $5 \mathrm{mM}$ glutamate, $2.5 \mathrm{mM}$ pyruvate, and $2 \mathrm{mM}$ malate. (Panov et al. 2009, 2011a, b). The results are presented as Mean $\pm \mathrm{SE}, \mathrm{n}=3$, and show the rates of ROS production in pmol $\mathrm{H}_{2} \mathrm{O}_{2} /$ minute/mg mitochondrial protein. Additions: $5 \mu \mathrm{M}$ Amplex red, $1 \mathrm{U}$ of horse radish peroxidase, $50 \mathrm{U}$ of superoxide dismutase (Sigma), $0.05 \mathrm{mg}$ mitochondria, glutamate $5 \mathrm{mM}$ + malate $2 \mathrm{mM}(\mathrm{G}+\mathrm{M})$; pyruvate $2.5 \mathrm{mM}+$ malate $2 \mathrm{mM}(\mathrm{P}+\mathrm{M})$; glutamate $5 \mathrm{mM}$ + pyruvate $2.5 \mathrm{mM}$ + malate $2 \mathrm{mM}(\mathrm{G}+\mathrm{P}+\mathrm{M})$; succinate $5 \mathrm{mM}(\mathrm{S})$; succinate $5 \mathrm{mM}$ + glutamate $5 \mathrm{mM}+$ pyruvate $2.5 \mathrm{mM}$ + malate $2 \mathrm{mM}(\mathrm{S}+\mathrm{G}+\mathrm{P}+\mathrm{M})$. Statistics: ${ }^{* *} p<0.01$; ${ }^{* * *} p<0.001$. For each year the data were compared with the rates of ROS production with glutamate + malate.

Fig. 5. Comparison of ROS production by wild type brain and spinal cord mitochondria, isolated in 2007 and 2010, oxidizing different substrates and substrate mixtures.

In 2008 we observed that BM and SCM from the wild type rats displayed a metabolic pattern that was different from the one described above. To highlight the differences in metabolic features of BM and SCM, we present data restricted to 2007, when significant mitochondrial dysfunctions in tgBM and tgSCM were observed as described in (Panov et al. 2011b), and 2010, when the tgSOD1 rat line failed to develop the disease features, and mitochondria showed little or no dysfunction as compared with the corresponding wild type animals. The related metabolic properties of the BM and SCM isolated from wild type animals in 2007 are presented and compared with those of 2010 in figures 5A and 5B.

Figure 5A compares ROS production by WT-BM isolated in 2007 and 2010. Of notice, the rate of ROS production by WT-BM isolated in 2010 was 3.5 fold higher than WT-BM isolated in 2007. However, in 2010 there was no differences in State 4 respiration (not shown) and ROS production (Fig. 5A) when BM oxidized glutamate + malate, pyruvate + malate or glutamate + pyruvate + malate. In contrast to WT-BM isolated in 2007, the much higher basic rate of ROS production supported by glutamate + malate in 2010 was inhibited by malonate to the level close to that in 2007 (Fig. 6). Similarly, in 2010 malonate inhibited ROS production in BM oxidizing glutamate + pyruvate + malate (Fig. 6 ) and pyruvate (not shown). 
In contrast to WT-BM isolated in 2007, the WT-BM isolated in 2010 produced ROS supported by succinate at much lower rates than with glutamate + pyruvate + malate (Fig. 5A). Addition of glutamate + pyruvate + malate to the WT-BM -2010 oxidizing succinate stimulated ROS production only to the level with glutamate + malate (Fig. 5A). Similar metabolic features were also observed with the WT-SCM isolated in 2010, although the differences from 2007 WT-SCM were smaller than for the BM (Fig 5B). It is important to note that in 2010 WT-SCM generated ROS with different substrates at the same levels as WT-BM, whereas in 2007 the WT-SCM generated significantly more ROS than the corresponding WT-BM (Fig. 5A and 5B. Note the scale difference between the figures).

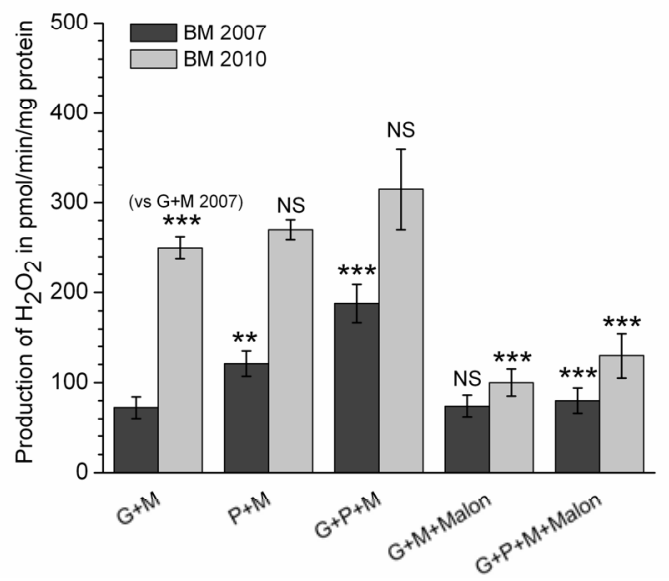

Incubation conditions and designations as described in Fig. 5. Malonate $5 \mathrm{mM}$ was added before mitochondria. Dark gray - BM isolated in 2007, light gray columns - BM isolated in 2010. Statistics: *** $p$ $<0.001$, NS - not significant difference. The dark columns and grey columns were compared with the corresponding column representing ROS production with glutamate and malate, taken as $100 \%$.

Fig. 6. Effect of malonate on ROS production by wild type brain mitochondria, isolated in 2007 and 2010, oxidizing glutamate + malate, pyruvate + malate, and glutamate + pyruvate + malate.

The sensitivity of the State 4 ROS production supported by either pyruvate or glutamate to malonate (Fig, 6; Panov et al. 2009) demonstrates that at least with BM and SCM both glutamate and pyruvate cannot be regarded as "pure complex I substrates", as is commonly accepted. In BM and SCM during oxidation of glutamate or pyruvate, and particularly when glutamate and pyruvate are present simultaneously, significant amounts of a-ketoglutarate can be formed in transaminase reactions, which is further converted to succinate (Balasz, 1965; Panov et al. 2009).

\section{Effects of metabolic phenotype on ROS production by tgBM and tgSCM}

Figure 7A shows generation of ROS by tgBM and tgSCM isolated from tgSOD1 rats in 2007, and figure $7 \mathrm{~B}$ presents corresponding results for tgBM and tgSCM isolated from tgSOD1 rats in 2010. The figures clearly show that in spite of higher basic ROS production with 
glutamate and pyruvate by BM and SCM in 2010 (Fig. 5A and 5B), the overall rates of ROS generation with physiologically relevant substrate mixture - glutamate + pyruvate + malate were 5 times lower for tgBM and 10 times for $\operatorname{tgSCM}$, when compared with transgenic mitochondria in 2007 (Fig. 7A and 7B).
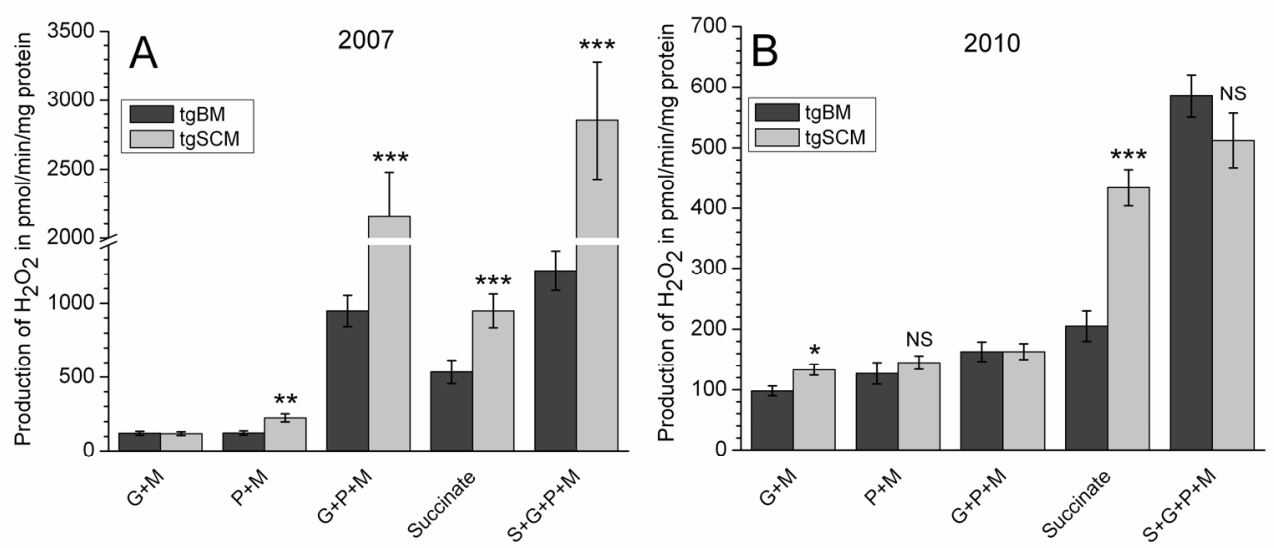

A. 2007; B. 2010. Dark grey - brain mitochondria, light gray - spinal cord mitochondria. Incubation conditions as in Fig. 5. Statistics: ${ }^{*} p<0.05$; ${ }^{* *} p<0.01$; ${ }^{* * *} p<0.001$. The data for tgSCM were compared with the corresponding results for $\operatorname{tgBM}$.

Fig. 7. Generation of ROS by brain and spinal cord mitochondria from tgSOD1 rats, isolated in 2007 and 2010, oxidizing various substrates.

Similar multiple-fold differences in ROS production existed also with succinate and succinate containing substrate mixtures (Figs. 7A, 7B). In tgBM and tgSCM, the increases in ROS generation were substrate specific and depended on activity of SDH. These results led us to conclusion that changes in the metabolic phenotype of neuronal mitochondria, which occurred in 2008, resulted in a dramatic decrease in production of ROS in tgSOD1 rats.

\section{Hydrogen peroxide is the major species to cause oxidative stress in tgSOD1 mitochondria}

One of the distinctions of BM and SCM is a very high activity of MnSOD (SOD2) (Panov et al., 2009, 2011a, 2011b), which is distinct from the heart and skeletal muscle mitochondria (Muller et al., 2008). Even at very high rates of ROS production, such as shown in Figures 4 and $5 \mathrm{~A}, 5 \mathrm{~B}$, addition of external SOD did not increase fluorescence of resorufin. The high activity of SOD2 means that $\mathrm{BM}$ and SCM effectively eliminate superoxide radicals from the matrix by converting them to $\mathrm{H}_{2} \mathrm{O}_{2}$. Therefore, we suggest that the major damaging factor in tgSOD1 motor neurons is $\mathrm{H}_{2} \mathrm{O}_{2}$. It was shown that $\mathrm{H}_{2} \mathrm{O}_{2}$ can interact with $\mathrm{Cu}, \mathrm{Zn}-\mathrm{SOD}$ (SOD1) resulting in peroxidase activity of SOD1 (Liochev, Fridovich, 2004), formation of strong oxidant $\mathrm{CO}_{3} \cdot$ radical (reviewed in Valentine et al., 2005), enzyme inactivation, release of $\mathrm{Cu}^{2+}$, protein oxidation and aggregation (Ramirez et al., 2009, Durer et al., 2009). At this point, the damaging effects of $\mathrm{H}_{2} \mathrm{O}_{2}$ will be increased dramatically because $\mathrm{Cu}^{2+}$ ions are several orders more active than $\mathrm{Fe}^{2+}$ in Fenton-like reaction with $\mathrm{H}_{2} \mathrm{O}_{2}$ (Dikalov et al., 2004), which will produce hydroxyl radical-like species and further drive lipid peroxidation, 
protein damage and promote mitochondrial dysfunction. Loss of metals by mutant SOD1 leads to formation of amyloid-like aggregates (Durer et al., 2009). Mutations in SOD1 amplify reactions with $\mathrm{H}_{2} \mathrm{O}_{2}$, increase the lifetime of incorrectly folded states, and if exposed to even mild oxidative stress, incorrect disulfide links form and stabilize larger aggregates that may be resistant to the degradation by the quality control machinery of the cell, and thus increase association with mitochondria (Field et al., 2003; Furukawa, O'Halloran, 2008).

\section{Proposed mechanisms of increased ROS production in tgSOD1 mitochondria}

There is strong evidence that tgSOD1 selectively binds to the outer (Vande Velde et al., 2008) and inner mitochondrial membranes (Liu et al., 2004; Ahtoniemi et al., 2008). Mutant SOD1 protein associated with mitochondria forms cross-linked oligomers and causes a shift in the redox state of respiratory components (Ferri et al., 2006). We propose a mechanism by which tgSOD1 might increase generation of ROS associated with reverse electron transport. The hypothesis is based on our recently published data on the effects of cholesterol $\beta$-Dglucoside and cycad phytosterol glucosides on ROS generation by BM (Panov et al., 2010b). These compounds are neurotoxic and suspected as the cause of the cluster of neurodegenerative disorders in the western Pacific termed amyotrophic lateral sclerosisparkinsonism dementia complex (ALS-PDC) (Wilson et al., 2002). When added in vitro to mitochondria, cholesterol $\beta$-D-glucoside increased ROS production, which was specifically dependent on activity of SDH. Cholesterol $\beta$-D-glucoside is known to diminish the surface area of the membranes and thus affect the activity of the membrane's enzymes (Deliconstantinos et al., 1989). Here we suggest, that tgSOD1 upon its interaction with the mitochondria may change physical-chemical properties of the membranes and increase the rate of reverse electron transport in a way similar to that of cholesterol $\beta$-D-glucoside.

\section{Oxidative stress increases sensitivity of mitochondria to $\mathrm{Ca}^{2+}$-dependent excitotoxicity}

Increased oxidative stress makes mitochondria more sensitive to the $\mathrm{Ca}^{2+}$-induced permeability transition, which may initiate apoptotic or necrotic cell death (Halestrap et al., 2000; Nicholls, 2008b, 2009). Mitochondria from tgSOD1 animals have high sensitivity to the deleterious effects of calcium (Martin et al., 2009). SCM are particularly sensitive to calcium overload (Sullivan et al., 2004, Panov et al., 2011a). This scenario becomes very likely to occur in tgSOD1 animals in view of the fact that spinal cord tissue contains 8 times more calcium than brain tissue (Panov et al., 2011a). We estimated that when normalized for 1 gram of tissue, $\mathrm{BM}$ could sequester several times more $\mathrm{Ca}^{2+}$ than was available in the whole tissue. SCM, on the other hand, could sequester only approximately $20 \%$ of the total spinal cord tissue $\mathrm{Ca}^{2+}$ (Panov et al., 2011a). We suggest that the high content of $\mathrm{Ca}^{2+}$ is necessary to hold together the sheets of myelin, which protects the neurons. We have shown recently that increased oxidative stress promotes demyelination in brains of OXYS rats with genetically accelerated aging, which was ameliorated by feeding of animals with malate (Kolosova et al. 2011). Underwood et al. (2010), using magnetic resonance imaging, have shown signs of demyelination in the lumbar spinal cord of ALS-affected SOD1 mice, which were limited to white matter tracts arising from the motor neurons, whereas sensory white matter fibers were preserved. Damages to myelin sheets of motor neurons may evidently 
release large amounts of calcium. The tissue calcium content in the spinal cord from presymptomatic tgSOD1 rats was diminished by 26\% (Panov et al., 2011b). Thus, oxidatively damaged mitochondria may encounter increased amounts of $\mathrm{Ca}^{2+}$ released during demyelination and undergo permeability transition. Halestrap (2005) has pointed out that when mitochondria massively undergo permeability transition, the cells will die by necrosis, which was documented Martin et al.(2009) for ALS animals.

\section{Conclusions}

The results presented by us in this and other papers (Panov et al., 2009, 20011a, 2011b) lead us to suggest the role of the brain and spinal cord mitochondria in the loss of motor neurons in ALS. We hypothesize that increased oxidative stress associated with specific metabolic phenotypes, which promote reverse electron transport due to reduction of the membrane pool of ubiquinone by succinate (Panov et al., 2009, 2011a, 2011b) or fatty acids (Panov et al., 2010c), is a prerequisite for cases of sporadic ALS. The energy-dependent reverse electron transport is a way of dissipation of the mitochondrial membrane potential, which increases the rate of resting mitochondrial respiration. In mammals, the standard metabolic rate depends on the intrinsic (in state 4) mitochondrial proton conductivity (Rolfe \& Brown , 1997). Therefore in patients with ALS hypermetabolism could be associated with the systemically increased dissipation of mitochondrial membrane potential. The specific vulnerability of motor neurons in ALS is, more likely than not, associated with the specific features of spinal cord described in Panov et al. (2011a, 2011b).

Normally, SCM produce significantly more ROS than BM when oxidizing physiologically relevant mixture of neuromediator glutamate and the tricarboxylic acid cycle substrates pyruvate, succinate and malate. Mutated SOD1 is extremely sensitive to the damaging effect of $\mathrm{H}_{2} \mathrm{O}_{2}$, which in $\operatorname{tgBM}$ and tgSCM were dramatically increased. This results in demetallation of mSOD1 and association with mitochondria, thus changing the physical properties of the mitochondrial membranes and further enhancing production of ROS. Increased oxidative stress initiates damage to myelin and released the tissue calcium. Finally, oxidatively damaged mitochondria undergo the $\mathrm{Ca}^{2+}$-induced permeability transition, and motor neurons die by apoptotic or necrotic pathway. Thus, mitochondria are early and directly involved in the pathogenesis of ALS. We suggest that sporadic ALS is preferentially acquired by individuals with the mitochondrial metabolic phenotype, that promotes very high levels of ROS production. In individuals with mutated SOD1 gene, the abnormal SOD1 protein has high sensitivity to deleterious effect of $\mathrm{H}_{2} \mathrm{O}_{2}$ and the disease may develop even at normal levels of ROS production.

\section{Proposals for future studies}

The results and the hypothesis presented in this article highlight the importance to consider determination of metabolic phenotypes together with the disease mechanisms when working with patients or animal models of the ALS.

\section{Acknowledgements}

The authors thank the Carolinas HealthCare Foundation and Carolinas ALS Research Fund for financial support of this study. The authors thank Dr. Richelle Hemendinger and Dr. 
Nataliya Kubalik for testing in 2010 the tgSOD1 rats for the time of development of ALS symptoms.

\section{References}

Abeles, Moshe. Corticonics: Neural Circuits of the Cerebral Cortex. Cambridge Univ. Press, 1991 ISBN 0521374766

Ahtoniemi, T., Jaronen, M., Keksa-Goldsteine, V., Goldsteins, G., \& Koistinaho, J. (2008) Mutant SOD1 from spinal cord of G93A rats is destabilized and binds to inner mitochondrial membrane. Neurobiol. Dis. 32 (3), 479-485

Attwell D., \& Laughlin S.B. (2001) An energy budget for signaling in the grey matter of the brain. J Cereb Blood Flow Metab. 21, 1133-1145

Auger, C. \& Attwell, D. (2000) Fast removal of synaptic glutamate by postsynaptic transporters. Neuron. 28 (2), 547-558

Avossa, D., Grandolfo, M., Mazzarol, F., Zatta, M. \& Ballerini, L. (2006) Early signs of motoneuron vulnerability in a disease model system: Characterization of transverse slice cultures of spinal cord isolated from embryonic ALS mice. Neuroscience. 138 (4), 1179-1194

Bacman, S.R., Bradley, W.G. and Moraes, C.T. (2006) Mitochondrial involvement in amyotrophic lateral sclerosis: Trigger or target? Mol. Neurobiol. 33 (2), 113-131

Balazs, R. (1965) Control of glutamate metabolism. The effect of pyruvate. J. Neurochem. 12, 63-76

Balazs R. (1965) Control of glutamate oxidation in brain and liver mitochondrial systems. Biochem. J. 95, 497-508

Barber, S. C. \& Shaw, P.J. (2010) Oxidative stress in ALS: key role in motor neuron injury and therapeutic target. Free Radic. Biol. Med. 48(5), 629-641

Bendotti, C., \& Carri, M.T. (2004) Lessons from models of SOD1-linked familial ALS. Trends Mol. Med. 10 (8), 393-400

Berkich, D. A., Ola, M.S., Cole, J., Sweatt, A.J., Hutson, S.M., \& LaNoue, K.F. (2007) Mitochondrial transport proteins of the brain. J. Neurosci. Res. 85 (15), 3367-3677

Bertamini, M., Marzani, B., Guarneri, R., Guarneri, P., Bigini, P., Mennini, T. \& Curti, D. (2002) Mitochondrial oxidative metabolism in motor neuron degeneration (mnd) mouse central nervous system. Eur. J. Neurosci. 16 (12), 2291-2296

Bouteloup, C., Desport, J.C., Clavelou, P., Guy, N., Derumeaux-Burel, H., Ferrier, A. \& Couratier, P. (2009) Hypermetabolism in ALS patients: an early and persistent phenomenon. J. Neurol. 256 (8), 1236-1242

Braitenberg, V., \& Schüz, A. (1998) Cortex: statistics and geometry of neuronal connectivity, 2nd ed. Berlin: Springer.

Brasnjo, G., \& Otis, T.S. (2004) Isolation of glutamate transport-coupled charge flux and estimation of glutamate uptake at the climbing fiber-purkinje cell synapse. Proc. Natl. Acad. Sci. USA. 101, 6273-6278

Bruijn, L.I., Miller, T.M., \& Cleveland, D.W. (2004) Unraveling the mechanisms involved in motor neuron degeneration in ALS. Annu. Rev. Neurosci. 27, 723-749

Damiano, M., Starkov, A.A., Petri, S., Kipiani, K., Kiaei, M., Mattiazzi, M., Beal, F. M., \& Manfredi, G. (2006) Neural mitochondrial Ca capacity impairment precedes the onset of motor symptoms in G93A Cu/Zn-superoxide dismutase mutant mice. J. Neurochem. 96, 1349-1361 
Dave, K.R., Bradley, W.G., \& Perez-Pinzon, M.A. (2003) Early mitochondrial dysfunction occurs in motor cortex and spinal cord at the onset of disease in the Wobbler mouse. Exp Neurol. 182, 412-420

Deliconstantinos, G, Kopeikina, L, \&Villiotou, V. 1989. Evoked effects of cholesterol binding on integral proteins and lipid fluidity of dog brain synaptosomal plasma membranes. Biochem. Cell. Biol. 67 (1), 16-24

Desport, J. C., Torny, F., Lacoste, M., Preux, P.M. \& Couratier, P. (2005). Hypermetabolism in ALS: correlations with clinical and paraclinical parameters. Neurodegener. Dis. 2 (3-4), 202-207

Dikalov, S. I., Vitek, M.P. \& Mason, R.P. (2004). Cupric-amyloid beta peptide complex stimulates oxidation of ascorbate and generation of hydroxyl radical. Free Radic. Biol. Med. 36 (3), 340-347

Dupuis, L., Gonzalez de Aguilar, J.L., Echaniz-Laguna, A., Eschbach, J., Rene, F., Oudart, H., Halter, B., Huze, C., Schaeffer, L., Bouillaud, F., \& Loeffler, J.P. (2009) Muscle mitochondrial uncoupling dismantles neuromuscular junction and triggers distal degeneration of motor neurons. PLoS One. 4 (4), e5390

Durer, Z.A.O., Cohlberg, J.A., Dinh, P., Padua, S., Ehrenclou, K., Downes, S., Tan, J.K., Nakano, Y., Bowman, C.J., Hoskins, J.L., Kwon, C., Mason, A.Z., Rodriguez, J.A., Doucette, P.A., Shaw, B.F., \& Valentine, J.S. (2009) Loss of Metal Ions, Disulfide Reduction and Mutations Related to Familial ALS Promote Formation of AmyloidLike Aggregates from Superoxide Dismutase. PLoS One. 4 (3), e5004

Ebert, D., Haller, R.G. \& Walton, M.E. (2003) Energy contribution of octanoate to intact rat brain metabolism measured by 13C nuclear magnetic resonance spectroscopy. $J$. Neurosci. 23 (13), 5928-5935

Echaniz-Laguna, A., Zoll, J., Ponsot, E., N'Guessan, B., Tranchant, C., Loeffler, J.P. \& Lampert, E. (2006) Muscular mitochondrial function in amyotrophic lateral sclerosis is progressively altered as the disease develops: a temporal study in man. Exp. Neurol. 198 (1), 25-30

Field, L. S., Y. Furukawa, T. V. O'Halloran and V. C. Culotta (2003). Factors controlling the uptake of yeast copper/zinc superoxide dismutase into mitochondria. J. Biol. Chem. 278 (30), 28052-28059

Fischer, L.R., Igoudjil, A., Magrané, J., Li, Y., Hansen, J.M., Manfredi, G., Glass, J.D. (2011) SOD1 targeted to the mitochondrial intermembrane space prevents motor neuropathy in the Sod1 knockout mouse. Brain. 134 (Pt 1),196-209

Furness, D. N., Dehnes, Y., Akhtar, A.Q., Rossi, D.J., Hamann, M., Grutle, N.J., Gundersen, V., Holmseth, S., Lehre, K.P., Ullensvang, K., Wojewodzic, M., Zhou, Y., Attwell, D. \& Danbolt, D.C. (2008) A quantitative assessment of glutamate uptake into hippocampal synaptic terminals and astrocytes: New insights into a neuronal role for excitatory amino acid transporter 2 (EAAT2). Neuroscience. 157 (1), 80-94

Furukawa, Y. \& O'Halloran, T.V. (2006) Posttranslational modifications in Cu,Zn-superoxide dismutase and mutations associated with amyotrophic lateral sclerosis. Antioxid Redox Signal. 8 (5-6), 847-867

Gershoni, M., Templeton, A.R. \& Mishmar, D. (2009) Mitochondrial bioenergetics as a major motive force of speciation. Bioessays. 31 (6), 642-650

Gurney, M.E., Pu, H., Chiu, A.Y., Dal Canto, M.C., Polchow, C.Y., Alexander, D.D., Caliendo, J., Hentati, A., Kwon, Y.W., \& Deng, H.X. (1994) Motor neuron degeneration in mice that express a human $\mathrm{Cu}, \mathrm{Zn}$ superoxide dismutase mutation. Science. 264 (5166), 1772-1775 
Halestrap, A.P., Doran, E., Gillespie, J,P.,b \& O'Toole, A. (2000) Mitochondria and cell death. Biochem. Soc. Trans. 28 (2), 170-177.

Halestrap, H. A pore way to die. (2005) Nature. 434, 578-579

Heath P.R. \& Shaw P.J. (2002) Update on the glutamatergic neurotransmitter system and the role of excitotoxicity in amyotrophic lateral sclerosis. Muscle Nerve. 26, 438-458

Hertz, L. (2004) Intercellular metabolic compartmentation in the brain: past, present and future. Neurochem Int. 45, (2-3), 285-296

Higgins C.M., Jung C., Ding H. \& Xu Z. (2002) Mutant Cu, Zn superoxide dismutase that causes motoneuron degeneration is present in mitochondria in the CNS. J. Neurosci. 22, RC215

Howland, D.S., Liu, J., She, Y., Goad, B., Maragakis, N.J., Kim, B., Erickson, J., Kulik, J., DeVito, L., Psaltis, G., DeGennaro, L.J., Cleveland, D.W., Rothstein, J.D. (2002) Focal loss of the glutamate transporter EAAT2 in a transgenic rat model of SOD1 mutantmediated amyotrophic lateral sclerosis (ALS). Proc. Natl. Acad. Sci. USA. 99, 16041609.

Israelson, A., Arbel, N., Da Cruz, S., Illeva, H., Yamanaka, K., Shoshan-Barmatz, V. \& Cleveland, D.W. (2010) Misfolded mutant SOD1 directly inhibits VDAC1 conductance in a mouse model inherited ALS. Neuron, 67, 575-587

Jaarsma D. (2006) Swelling and vacuolisation of mitochondria in transgenic sod1-als mice: A consequence of supranormal sod1 expression? Mitochondrion. 6 (1), 48-49

Jung, C., Higgins, C.M.J. \& Xu, Z. (2002) A quantitative histochemical assay for activities of mitochondrial electron transport chain complexes in mouse spinal cord sections. J. Neurosci. Methods. 114 (2), 165-172

Kirkinezos, I. G., Bacman, S.R., Hernandez, D., Oca-Cossio, J., Arias, L.J., Perez-Pinzon, M.A., Bradley, W.G. \& Moraes, C.T. (2005) Cytochrome c association with the inner mitochondrial membrane is impaired in the CNS of G93A-SOD1 mice. J. Neurosci. $25,164-172$

Kolosova, N.G., Akulov, A.E., Stefanova, N.A., Moshkin, M.P., Savelov, A.A., Koptyug, I.V., Panov, A.V. \& Vavilin, V.A. (2011) Effect of malate on development of rotenoneinduced brain changes in Wistar and OXYS rats: An MRI study. Doklady Biol. Sci. $437,1-4$

Krasnianski, A., Deschauer, M., Neudecker, S., Gellerich, F.N., Muller, T., Schoser, B.G., Krasnianski, M. \& Zierz, S. (2005) Mitochondrial changes in skeletal muscle in amyotrophic lateral sclerosis and other neurogenic atrophies. Brain. 128 (Pt 8), 18701876

Kwong, L.K. \& Sohal, R.S. (1998) Substrate and site specificity of hydrogen peroxide generation in mouse mitochondria. Arch. Biochem. Biophys. 350 (1), 118-126

Liochev, S. I. \& Fridovich, I. (2004) CO2 enhanced peroxidase activity of SOD1: the effects of pH. Free Radic. Biol. Med. 36 (11), 1444-1447

Liu, J., Lillo, C., Jonsson, P.A., Vande Velde, C., Ward, C.M., Miller, T.M., Subramaniam, J.R., Rothstein, J.D., Marklund, S., Andersen, P.M., Brannstrom, T., Gredal, O., Wong, P.C., Williams, D.S. \& Cleveland, D.W. (2004) Toxicity of familial ALSlinked SOD1 mutants from selective recruitment to spinal mitochondria. Neuron. $43,5-17$

Magrane, J. \& Manfredi, G. (2009) Mitochondrial function, morphology, and axonal transport in amyotrophic lateral sclerosis. Antioxidants $\mathcal{E}$ Redox Signaling. 11 (7), 1615-1626 
Martin, L.J., Liu, Z., Chen, K., Price, A.C., Pan, Y., Swaby, J.A. \& Golden, W.C. 2007. Motor neuron degeneration in amyotrophic lateral sclerosis mutant superoxide dismutase-1 transgenic mice: mechanisms of mitochondriopathy and cell death. $J$. Comp. Neurol. 500 (1), 20-46

Martin, L.J., Gertz, B., Pan, Y., Price, A.C., Molkentin, J.D. \& Chang, Q. (2009) The mitochondrial permeability transition pore in motor neurons: Involvement in the pathobiology of ALS mice. Experim. Neurol. 218 (2), 333-346

Massie, A., Cnops, L., Smolders, I., McCullumsmith, R., Kooijman, R., Kwak, S., Arckens, L. \& Michotte, Y. (2008) High-affinity $\mathrm{Na}+/ \mathrm{K}+$-dependent glutamate transporter EAAT4 is expressed throughout the rat fore- and midbrain. J Comp Neurol. 511 (2), $155-172$

Matsumoto, A., Okada, Y., Nakamichi, M., Nakamura, M., Toyama, Y., Sobue, G., Nagai, M., Aoki, M., Itoyama, Y. \& Okano, H. (2006) Disease progression of human SOD1 (G93A) transgenic ALS model rats. J. Neurosci. Res. 83 (1), 119-133

Mitchell, P. (1977) Vectorial chemiosmotic processes. Ann. Rev. Biochem. 46, 996-1005

Morota, S.; Hansson, M.J.; Ishii, N.; Kudo, Y.; Elmer, E.; Uchino, H. (2007) Spinal cord mitochondria display lower calcium retention capacity compared with brain mitochondria without inherent differences in sensitivity to cyclophilin D inhibition. J Neurochem. 103 (5), 2066-2076, 2007

Muller, F.L., Liu, Y., Abdul-Ghani, M.A., Lustgarten, M.S., Bhattacharya, A., Jang, Y.C. \& Van Remmen, H. (2008) High rates of superoxide production in skeletal-muscle mitochondria respiring on both complex I- and complex II-linked substrates. Biochem. J. 409 (2), 491-499.

Muller, F.L.; Song, W.; Jang, Y.C.; Liu, Y.; Sabia, M.; Richardson, A. \& Van Remmen, H. (2007) Denervation-induced skeletal muscle atrophy is associated with increased mitochondrial ROS production. Am. J. Physiol. Regul. Integr. Comp. Physiol. 293, 3, R1159-R1168

Nakano, Y., Hirayama, K. \& Terao, K. (1987) Hepatic ultrastructural changes and liver dysfunction in amyotrophic lateral sclerosis. Arch. Neurol. 44 (1), 103-106

Nicholls, D. G. (1993). The glutamatergic nerve terminal. Eur. J. Biochem. 212 (3), 613-631

Nicholls, D. G. (2008) Oxidative stress and energy crises in neuronal dysfunction. Ann. N. Y. Acad. Sci. 1147, 53-60

Nicholls, D. G. (2008) Forty years of Mitchell's proton circuit: From little grey books to little grey cells. Biochim. Biophys. Acta. 1777 (7-8), 550-556

Nicholls, D. G. (2009) Mitochondrial calcium function and dysfunction in the central nervous system. Biochim. Biophys. Acta. 1787 (11), 1416-142

Norenberg, M. D. \& Martinez-Hernandez, A. (1979) Fine structural localization of glutamine synthetase in astrocytes of rat brain. Brain Res. 161 (2), 303-310

Panov, A., Dikalov, S., Shalbuyeva, N., Hemendinger, R., Greenamyre, J.T. \& Rosenfeld, J. (2007) Species and tissue specific relationships between mitochondrial permeability transition and generation of ROS in brain and liver mitochondria of rats and mice. Am. J. Physiol. Cell. Physiol. 292 (2), C708-C718

Panov, A., Schonfeld, O., Dikalov, S., Hemendinger, R., Bonkovsky, H.L. \& Brooks, B.R. (2009) The neuromediator glutamate, through specific substrate interactions, enhances mitochondrial ATP production and reactive oxygen species generation in nonsynaptic brain mitochondria. J. Biol. Chem. 284 (21), 14448-14456.

Panov, A.V., Vavilin, V.A., Lyalkhovich, V.V., Brooks, B.R., Bonkovsky, H.L. (2010a) Effects of defatted bovine serum albumin on respiratory activities of brain and liver 
mitochondria from C57Bl/6G mice and Sprague Dawley rats. Bull. Exp. Biol. Med. 149 (2), 187-190

Panov, A., Kubalik, N., Brooks, B.R. \& Shaw, C.A. (2010b) In vitro effects of cholesterol $\beta$-Dglucoside, cholesterol and cycad phytosterol glucosides on respiration and reactive oxygen species generation in brain mitochondria. J. Membr. Biol. 237, 71-77

Panov, A., Kubalik, N., \& Brooks, B.R. (2010c) Effects of palmitoyl carnitine on brain, spinal cord and heart mitochondria from wild type and transgenic SOD1 rats. 21 st International Symposium on ALS/MND, Orlando 11-13 December, 2010. Amyotrophic Lateral Sclerosis. 11 (Suppl. 1), 115

Panov, A.V., Kubalik, N., Zinchenko, N., Hemendinger R., Brooks B.R. \& Bonkovsky, H.L. (2011a) Metabolic and functional differences between brain and spinal cord mitochondria underlie different predisposition to pathology. Am. J. Physiol. Regul. Integr. Comp. Physiol. 300 (4), R844-R854

Panov, A., Kubalik, N., Zinchenko, N., Hemendinger, R., Dikalov, S. \& Bonkovsky, H.L. (2011b) Respiration and ROS production in brain and spinal cord mitochondria of transgenic rats with mutant G93A Cu/Zn-Superoxide dismutase gene. Neurobiol. Dis. $44,53-62$

Pardo, B., Contreras, L., Serrano, A., Ramos, M., Kobayashi, K., Iijima, M., Saheki, T. \& Satrustegui, J. (2006). Essential role of aralar in the transduction of small ca2+ signals to neuronal mitochondria. J. Biol. Chem. 281 (2), 1039-1047

Pedrini, S., Sau, D., Guareschi, S., Bogush, M., Brown, R.H., Jr., Naniche, N., Kia, A., Trotti, D. \& Pasinelli, P. (2010) ALS-linked mutant SOD1 damages mitochondria by promoting conformational changes in Bcl-2. Hum. Mol. Genet. 19 (15), 2974-2986

Pellerin, L., Bouzier-Sore, A.K., Aubert, A., Serres, S., Merle, M., Costalat, R. \& Magistretti, P.J. (2007) Activity-dependent regulation of energy metabolism by astrocytes: an update. Glia. 55 (12), 1251-1262

Przedborski S. (2004) Programmed cell death in amyotrophic lateral sclerosis: a mechanism of pathogenic and therapeutic importance. Neurologist. 10, 1-7

Ramirez, D.C., Gomez-Mejiba, S.E., Corbett, J.T., Deterding, L.J., Tomer, K.B. \& Mason, R.P. (2009) $\mathrm{Cu}, \mathrm{Zn}$-superoxide dismutase-driven free radical modifications: copper- and carbonate radical anion-initiated protein radical chemistry. Biochem. J. 417 (1), 341353

Rolfe, D.F.S. \& Brown, G.C. (1997) Cellular energy utilization and molecular origin of standard metabolic rate in mammals. Physiol. Rev. 77, 731-758

Rowland, L.P. \& Shneider, N.A. (2001) Amyotrophic lateral sclerosis. N. Engl. J. Med. 344 (22), 1688-1700

Shook, S.J. \& Pioro, E.P. (2009) Racing against the clock: Recognizing differentiating, diagnosing, and referring the amyotrophic lateral sclerosis patient. Ann. Neurol., 65 (suppl.), S10-S16

Starkov, A.A. (2008) The role of mitochondria in reactive oxygen species metabolism and signaling. Ann. New York Acad. Sci. 1147, 37-52

Stowe, D.F. \& Camara, A.K. (2009) Mitochondrial reactive oxygen species production in excitable cells: Modulators of mitochondrial and cell function. Antioxidants $\mathcal{E}$ Redox Signaling. 11 (6), 1381-1414

St-Pierre, J., Buckingham, J.A., Roebuck, S.J. \& Brand, M.D. (2002) Topology of superoxide production from different sites in the mitochondrial electron transport chain. J. Biol. Chem. 277 (47), 44784-44790 
Stolzenburg, J.U., Reichenbach, A. \& Neumann, M. (1989) Size and density of glial and neuronal cells within the cerebral neocortex of various insectivorian species. Glia. 2 (2), 78-84

Sullivan P.G., Rabchevsky, A.G., Keller, J.Y.N., Lovell, M., Sodhi, A., Hart, R.P. \& Scheffer, S.W. (2004) Intrinsic differences in brain and spinal cord mitochondria: implication for therapeutic interventions. J. Comparative Neurol. 474, 524-534

Suzuki, A., Stern, S.A., Bozdagi, O., Huntley, G.W., Walker, R.H., Magistretti, P.J. \& Alberini, C.M. (2011) Astrocyte-neuron lactate transport is required for long-term memory formation. Cell. 144 (5), 810-823

Tillakaratne N.J., Medina-Kauwe, L. \& Gibson, K.M. (1995) Gamma-aminobutyric acid (gaba) metabolism in mammalian neural and nonneural tissues. Comp. Biochem. Physiol. A Physiol. 112 (2), 247-263

Tateno M., Sadakata H., Tanaka M., Itohara S., Shin R.M., Miura M., Masuda M., Aosaki T., Urushitani M., Misawa H. \& Takahashi R. (2004) Calcium-permeable AMPA receptors promote misfolding of mutant SOD1 protein and development of amyotrophic lateral sclerosis in a transgenic mouse model. Hum. Mol. Genet. 13, 2183-2196

Tretter, L., Takacs, K., Hegedus, V. \& Adam-Vizi, V. (2007) Characteristics of alphaglycerophosphate-evoked $\mathrm{H} 2 \mathrm{O} 2$ generation in brain mitochondria. J. Neurochem. 100 (3), 650-663

Valentine, J.S., Doucette, P.A. \& Potter, S.Z. (2005) Copper-zinc superoxide dismutase and amyotrophic lateral sclerosis. Annu. Rev. Biochem. 74, 563-593

Vande Velde, C., Miller, T.M., Cashman, N.R. \& Cleveland, D.W. (2008) Selective association of misfolded ALS-linked mutant SOD1 with the cytoplasmic face of mitochondria. Proc. Natl. Acad. Sci. USA. 105 (10), 4022-4027

Von Lewinski, F. \& B. U. Keller (2005). Ca2+, mitochondria and selective motoneuron vulnerability: implications for ALS. Trends Neurosci. 28 (9), 494-500

Votyakova, T.V. \& Reynolds, I.J. (2001) $\Delta \Psi$-dependent and independent production of reactive oxygen species by rat brain mitochondria. J. Neurochem. 79, 266-277

Waagepetersen, H.S., Sonnewald. U., Larsson, O.M. \& Schousboe, A. (1999) Synthesis of vesicular GABA from glutamine involves TCA cycle metabolism in neocortical neurons. J. Neurosci. Res. 57 (3), 342-349

Wallace, D.C. (2001) Mouse models for mitochondrial disease. Am. J. Med. Genet. 106, 71-93

Wilson, J.M., Khabazian, I., Wong, M.C., Seyedalikhani, A., Bains, J.S., Pasqualotto, B.A., Williams, D.E., Andersen, R.J., Simpson, R.J., Smith, R., Craig, U.K., Kurland, L.T., \& Shaw, C.A. (2002) Behavioral and neurological correlates of ALS-parkinsonism dementia complex in adult mice fed washed cycad flour. Neuromolecular Med. 1 (3), 207-221

Wong-Riley, M.T. (1989) Cytochrome oxidase: An endogenous metabolic marker for neuronal activity. Trends Neurosci. 12 (3), 94-101

Xu, G-P., Dave, K.R., Moraes, C.T., Busto, R., Sick, T.J., Bradley, W.G. \& Perez-Pinzon, M.A. (2001) Dysfunctional mitochondrial respiration in the wobbler mouse brain. Neurosci. Letters. 300, 141-144

Yudkoff, M., Nelson, D., Daikhin, Y. \& Erecinska, M. (1994). Tricarboxylic acid cycle in rat brain synaptosomes. Fluxes and interactions with aspartate aminotransferase and malate/aspartate shuttle. J. Biol. Chem. 269 (44), 27414-27420.

Zoccarato, F., Cavallini, L., Bortolami, S. \& Alexandre, A. (2007) Succinate modulation of $\mathrm{H}_{2} \mathrm{O}_{2}$ release at NADH -ubiquinone oxidoreductase (Complex I) in brain mitochondria. Biochem. J. 406 (1), 125-129 
AMYOTROPHIC

LATERAL SCLEROSIS

Eaced by Marton H. maver

\section{Amyotrophic Lateral Sclerosis}

Edited by Prof. Martin Maurer
ISBN 978-953-307-806-9

Hard cover, 718 pages

Publisher InTech

Published online 20, January, 2012

Published in print edition January, 2012

Though considerable amount of research, both pre-clinical and clinical, has been conducted during recent years, Amyotrophic Lateral Sclerosis (ALS) remains one of the mysterious diseases of the 21 st century. Great efforts have been made to develop pathophysiological models and to clarify the underlying pathology, and with novel instruments in genetics and transgenic techniques, the aim for finding a durable cure comes into scope. On the other hand, most pharmacological trials failed to show a benefit for ALS patients. In this book, the reader will find a compilation of state-of-the-art reviews about the etiology, epidemiology, and pathophysiology of ALS, the molecular basis of disease progression and clinical manifestations, the genetics familial ALS, as well as novel diagnostic criteria in the field of electrophysiology. An overview over all relevant pharmacological trials in ALS patients is also included, while the book concludes with a discussion on current advances and future trends in ALS research.

\section{How to reference}

In order to correctly reference this scholarly work, feel free to copy and paste the following:

Alexander Panov, Nury Steuerwald, Valentin Vavilin, Svetlana Dambinova and Herbert L. Bonkovsky (2012). Role of Neuronal Mitochondrial Metabolic Phenotype in Pathogenesis of ALS, Amyotrophic Lateral Sclerosis, Prof. Martin Maurer (Ed.), ISBN: 978-953-307-806-9, InTech, Available from:

http://www.intechopen.com/books/amyotrophic-lateral-sclerosis/role-of-neuronal-mitochondrial-metabolicphenotype-in-pathogenesis-of-als

\section{INTECH}

open science | open minds

\section{InTech Europe}

University Campus STeP Ri

Slavka Krautzeka 83/A

51000 Rijeka, Croatia

Phone: +385 (51) 770447

Fax: +385 (51) 686166

www.intechopen.com

\section{InTech China}

Unit 405, Office Block, Hotel Equatorial Shanghai

No.65, Yan An Road (West), Shanghai, 200040, China

中国上海市延安西路65号上海国际贵都大饭店办公楼405单元

Phone: +86-21-62489820

Fax: $+86-21-62489821$ 
(C) 2012 The Author(s). Licensee IntechOpen. This is an open access article distributed under the terms of the Creative Commons Attribution 3.0 License, which permits unrestricted use, distribution, and reproduction in any medium, provided the original work is properly cited. 